\title{
Duodenal perforation in women 60years of age following receipt of a non-steroidal anti- inflammatory drug
}

\section{Opinion}

Treatment with non-steroidal anti-inflammatory drugs (NSAIDs) is associated with an increased risk of peptic ulcer complications, but it is not clear whether some drugs are more likely than others to cause such complications.

Interventions to reduce the morbidity and mortality from upper gastrointestinal disease caused by the widespread use of non-steroidal anti-inflammatory drugs include educational methods aimed at reducing prescribing, co prescription of a mucosal protective drug such as misoprostol, and the use of paracetamol as an alternative analgesic. ${ }^{1,2}$ Another approach is to prescribe a drug associated with a comparatively low risk of gastrointestinal toxicity and use more toxic compounds only in the event of a poor clinical response to the first line drug. ${ }^{3,4}$ However, evaluation of the data on comparative risk is difficult. Published epidemiological studies have provided variable coverage of individual drugs, making them unsuitable for metaanalytical approaches that attempt to pool data across all studies.

12 studies that examined relative risks of gastrointestinal complications with a total of 14 nonsteroidal anti-inflammatory drugs and satisfied our criteria for inclusion. Twelve drugs had been included in two or more studies and 11 studies provided comparative data on ibuprofen and other agents. Two reports were unpublished at the time of writing: one was an update and reanalysis of a previously published paper; the other had been published only as an abstract. Three other studies were updated by the authors at the investigators' workshop or in subsequent correspondence. ${ }^{3-12}$

A 60 -year-old woman weighing 70pounds with a history of chronic obstructive pulmonary disease as well as a serious smoker has been vomiting for four days and two days before going to the hospital received a non-steroidal anti-inflammatory drug disc for a back pain. The patient was diagnosed with a duodenal perforation at her arrival at the hospital, as her vital signs were disturbed with a blood pressure of $80 / 60 \mathrm{mmHg}$ and a cardiac frequency of 118 . Ringers Lactate fluid was given for volume replenishment (deficit -10.7). Anesthesia with propofol 200mg, Fentanyl 0.1mg, Esmeron $100 \mathrm{mg}$, maintenance of anesthesia with Sevo $2.5 \%$, and maintenance and control of analgesia with an epidural catheter as originally $3 \mathrm{ml}$ Naropaine $0.75 \%$ was given. The surgery had duration of 2.5 hours, during which time the patient began metabolic acidosis. Five minutes after awakening, the patient experienced faint breathing and a drop in consciousness, and in $\mathrm{Ph}$ gas measurement $\mathrm{Ph}$ was 7.05. The patient was re-intubated, placed in mechanical ventilation for 4hours, given 15liters of Ringers, placed in levophed $(1: 100,60 \mathrm{ml} / \mathrm{h})$ to maintain hemodynamic stability. It was aero-bronchodilator intratracheally and a volume control (tidal volume 370 and frequency 22) which was modified into pressure support and was decoded 2 hours later. The diuresis was $3600 \mathrm{ml}$, ph 7.27 and the -7 th deficit. The patient had a good level of communication, good respiratory rate and analgesia and was transferred for follow-up in an increased care unit.
Volume 12 Issue I - 2019

Dalamagka Maria, Panagiotidis Anastasios

Department of Anaesthesiology, General University Hospital of Larissa, Greece

\section{Correspondence: Dalamagka Maria, Department of Anaesthesiology, General University Hospital of Larissa, Greece, Email mary.dalamaga@gmail.com}

Received: November 22, 2018 | Published: January 31, 2019

Appropriate clinical strategies could prevent many episodes of peptic ulcer bleeding: NSAIDs should be used only in patients who do not respond to other analgesics; the lowest possible doses should be used; and the least toxic NSAIDs should be selected.

\section{Acknowledgments}

None.

\section{Conflicts of interest}

Author declares there is no conflict of interest.

\section{References}

1. Silverstein FE, Graham DY, Senior JR, et al. Misoprostol reduces serious gastrointestinal complications in patients with rheumatoid arthritis receiving non-steroidal anti-inflammatory drugs. Ann Intern Med. 1995;123(4):241-249.

2. Bradley JD, Brandt KD, Katz BP. Comparison of an anti-inflammatory dose of ibuprofen, an analgesic dose of ibuprofen, and acetaminophen in the treatment of patients with osteoarthritis of the knee. $N$ Engl J Med. 1991;325(2):87-91.

3. Langman MJS, Weil J, Wainright P, et al. Risks of bleeding peptic ulcer associated with individual non-steroidal anti-inflammatory drugs. Lancet. 1994;343(8905):1075-1078.

4. Bateman DN. NSAIDs: time to re-evaluate gut toxicity. Lancet. 1994;343(8905):1051-1052.

5. Gabriel SE, Jaakkimainen L, Bombardier. Risk for serious gastrointestinal complications related to use of nonsteroidal anti-inflammatory drugs. A meta-analysis. Ann Intern Med. 1991;115(10):787-796.

6. Bollini P, Garcia-Rodriguez LA, Perez G, et al. The impact of research quality and study design on epidemiologic estimates of the effect of nonsteroidal anti-inflammatory drugs on upper gastrointestinal tract disease. Arch Intern Med. 1992;152(6):1289-1292.

7. Henry D, Dobson A, Turner C. Variability in the risk of major gastrointestinal complications from nonaspirin nonsteroidal antiinflammatory drugs. Gastroenterology. 1993;105(4):1078-1088.

8. Somerville K, Faulkner G, Langman M. Non-steroidal anti-inflammatory drugs and bleeding peptic ulcer. Lancet. 1986;1:462-464.

9. Carson JL, Strom BL, Morse ML, et al. The relative gastrointestinal toxicity of the nonsteroidal anti-inflammatory drugs. Arch Intern Med. 1987;147(6):1054-1059. 
10. Griffin MR, Piper JM, Daugherty JR, et al. Non-steroidal antiinflammatory drug use and increased risk for peptic ulcer disease in elderly persons. Ann Intern Med. 1991;114(4):257-263.

11. Laporte JR, Carne X, Vidal X, et al. Upper gastrointestinal bleeding in relation to previous use of analgesics and non-steroidal anti- inflammatory drugs. Catalan countries study on upper gastrointestinal bleeding. Lancet. 1991;337(8733):85-89.

12. Savage RL, Moller PW, Ballantyne CL, et al. Variation in the risk of peptic ulcer complications with nonsteroidal antiinflammatory drug therapy. Arthritis Rheum. 1993;36(1):84-90. 